\title{
Mapping spatial distribution of particulate matter using Kriging and Inverse Distance Weighting at supersites of megacity Delhi
}

\author{
Komal Shukla1, Prashant Kumar ${ }^{2}$, Gaurav S Mann', Mukesh Khare ${ }^{1,3} 1$ \\ ${ }^{1}$ Department of Civil Engineering, Indian Institute of Technology, Delhi, New Delhi, India \\ ${ }^{2}$ Global Centre for Clean Air Research (GCARE), Department of Civil and Environmental \\ Engineering, Faculty of Engineering and Physical Sciences, University of Surrey, Guildford \\ GU2 7XH, United Kingdom \\ ${ }^{3}$ Centre of Excellence for Research on Clean Air, Indian Institute of Technology, Delhi, New \\ Delhi, India
}

\begin{abstract}
Anthropogenic airborne particulates are among the major contributors to urban air pollution and pose a significant health risk. Particulate matter has emerged as a serious pollution threat in India, specifically to the capital-New Delhi. The objective of this study is to map $\mathrm{PM}_{2.5}$ profile using two widely used spatial interpolation techniques (Kriging and IDW) by predicting their concentrations at distinct unmonitored locations. The implemented methodology has a wide-scoped utility in the field of air pollution; especially in Low-Middle Income Countries where setting up new monitoring stations include financial/logistical/location problems. The generated maps can help in policy formulation and decision making by providing aid in $\mathrm{PM}_{2.5}$ visualisation of spatial and temporal variability. First phase of study involves prediction of concentrations at two sites (reinforcing the need for sustainable development of the city) using concentrations for 2015-2017.In the second phase, pollutant mixing ratios were obtained for four winter months between Nov-2017 to Feb-2018 at 17 monitoring stations. In this phase, predictions were made for 11 supersites (zones of important land-use). The average error of Kriging and IDW (taking both phases) was $\sim 22 \%$ and $24 \%$, respectively. The magnitude of change in the daily concentration was relatively negligible and annual trend can be identified.
\end{abstract}

Keywords: Spatial interpolation, Discrete predictions, Ordinary kriging (OK), Inverse distance weighted (IDW), Prediction accuracy, ASAP-Delhi project

\section{Research highlights}

- Application of interpolation techniques can improve the quality of air pollution mapping

- Two interpolation techniques were applied to predict concentrations at discrete sites in Delhi

- Particulate matter $\left(\mathrm{PM}_{2.5}\right)$ mapping for city of Delhi

- Cross-validation process and the percentage errors estimate the reliability of predictions

- Combination of these techniques with other tools and the data source is suggested

\footnotetext{
${ }^{1}$ Corresponding author: Address as above. Email: mukeshk@civil.iitd.ac.in
} 


\section{Introduction}

The impact of air pollution on human health in both developed and developing nations are significant (Chung et al., 2011; Kanada et al., 2013; Fotourehchi, 2016). Episodes of spikes in air pollution concentrations have increased in frequency over the last decade (Shukla et al., 2017; Cohen et al., 2017). Each year about 800,000 deaths and around 4.6 million lost lifeyears are caused by air pollution (WHO 2016). It has attracted attention from the Supreme Court of India (Rosencranz and Jackson, 2003), non-governmental organizations (Greenstone and Hanna, 2014) and numerous policymakers (Kandlikar and Ramachandran, 2000). In India, the prime air pollution monitoring agency is the Central Pollution Control Board (CPCB), which monitors air pollution through 731 nation-wide monitoring stations (CPCB, 2018). Delhi lacks significant natural water bodies, which intensifies the effect of $\mathrm{PM}_{2.5}$ among other pollutants and contributes to medical complications in various age groups. As per the latest policy of the Delhi government is the epitome of the integrated approach to smart cities, and its integrated systems need to function efficiently to ensure long lasting quality life for the city and the inhabitants (Silva et al., 2018).

Particulate matter (PM) is the net sum of all particles suspended in the air (Heal et al., 2012). The focus of this work remains on $\mathrm{PM}_{2.5}$, which is referred to PM that has an aerodynamic diameter of $\leq 2.5 \mu \mathrm{m}$ (Kumar et al., 2018). Air pollution from onsite burning of agricultural crop residue is one of the many causes of environmental hazard observed in northern India (Awasthi et al., 2011). Considerable significance is held by the phenomenon of the Asian Brown Cloud, and its multifarious impacts. It affects agriculture, health and climate change on both regional and global scale (Srinivasan and Gadgil, 2002). In cities such as Delhi, air pollution is attracting the attention from the administrators and policy makers, which has opened the way for a higher-level tactical approach to mitigate these problems (Kumar et al., 2017). The unavoidable migration towards the urban area gives way to analysing its effect on the natural resources and infrastructural capabilities of the cities (Silva and Mendes, 2012). Recent studies point out that vehicular particulate emissions have exhibited a decreasing trend in the last decade. But the overall particulate matter concentration has seen a consistent rise, adding to the significance of better inventory creation for it (Nagpure et al., 2016). A similar study in the Delhi region targeting particulate matter gives us the synergic interaction of various sources and what challenges interventions might face (Kumar et al., 2017). Accuracy did not depend of the nature of site, but adding constraints such as maximum values and daily variation to them can certainly provide presentable results. Physical characteristics of site data such as 
geography and concentration variation would be relevant if the factors such as wind speed, temperature dependence of particulate matter and topographical variations would be considered. Since the sites were not spread over a huge geographical area, these factors would not cause significant variation in the results.

The difference in accuracy is due to the value of the $\mathrm{PM}_{2.5}$ concentrations, and not due to nature of the land use of the sites. In another work, the health impacts of air pollution have been studied in various megacities of India, including Delhi, indicating how hospital visits are correlated with an increase in pollutant concentration (Kumar et al., 2013). $\mathrm{PM}_{2.5}$ estimations were achieved using two interpolation techniques: Kriging, which is a function of statistical stationarity; and Inverse distance weightage (IDW) that is a function of the distance of separation amongst the sites. In the field of marine pollution, Kriging regression models are used to create surface maps for biological contamination and its spreading. Currently spatial interpolation techniques are being used to obtain predicted surfaces for air pollutant concentration also, to obtain reliable high-resolution predictive concentration values for major pollutants.

Data collection and generation is highly desirable to estimate/predict the required pollutant (Bonzar et al., 1993). Moreover, high demand for urban air quality estimation models, which help in calculating pollutant concentration at a desired discrete location is present (Hurley at el., 2005). Local geography and the various meteorological factors such as wind speed, pressure, temperature, precipitation in the control volume enclosed by the atmospheric boundary layer, have a contrasting effect on pollutant estimation (Baklanov et al., 2010). Nevertheless, it is not possible to consider the synergic effect of all such factors during physical modelling. Hence, pollutant data across India from Nation-wide Ambient Air Quality Monitoring Network (NAAQM) program is relied upon. Moreover, the dispersion of these pollutants, rather randomly in the lower layer of the atmosphere also introduces a varying degree of uncertainty (Mallet and sportisse, 2008). The spatial and temporal distribution of the pollutants can be estimated using multiple basic laws of physical sciences such as equations of mass, energy, momentum conservation; but in addition to gas laws and thermodynamic parameters, one requires multiple boundary conditions at each grid boundary. In recent studies, kriging based regression model has been used to quantify the radioactive soil contamination.

Kriging based techniques have been used in structural analyses, specifically to analyse Timoshenko beams where conventional polynomial interpolation was usually used (Wong et 
al., 2018). Monte Carlo Techniques combined with Kriging have used for Reliability Analysis of Mechanical System Models. It has helped to overcome specific drawbacks of using small failure probabilities (Lelièvre et al., 2018). In a recent study in Central Italy, Kriging based regression model was used to quantify the geogenic radon potential and subsequent exposure risk from the contaminated soil (Giustini et al., 2019).Ordinary Kriging, Regression Kriging and Co-Kriging were used to map potentially toxic metal concentrations in Southern China $\mathrm{Xu}$ et al., 2019). In another recent study, Kriging regression models were used in estimating the surface contamination of biological origin (Rossi et al., 2017)

Metrological parameters such as wind speed are profoundly affected by the terrain of a site and these methods have also been previously modelled in various studies using unadorned methods such as IDW (Palomino and Martin, 1995). Earlier studies with spatial interpolation have observed significantly smaller errors when there are limited topographical variations across the study area. It has been seen during the assessment of parameters such as ambient temperature with spatial interpolation that, in case of mountainous region - the yielded errors are large in magnitude when compared to plain or rolling terrain (Kumari et al., 2016; Chung and Yun, 2004). Delhi has a complex terrain in terms of land use but has a fairly flat surface geographically, and hence the probability of predictions with large errors is modest.

Although among the two discussed methods, IDW is simpler as compared to Kriging, yet some studies observed it to outperform the latter (Vorapracha, et al., 2015). The satisfactory results obtained in the present study can form the basis of further evolution by hybrid algorithms such as random forest or neural networks to improve accuracy and reliability (Wu et al., 2018; Qi et al., 2018). These techniques can also be combined with data from low-cost sensors to improve monitoring networks worldwide (Dünnebeil, et al., 2017), and to explore application of Gaussian framework on Kriging in Delhi region as applied in other Asian locations (Park, 2016).

Even in the latest research works on the prediction of pollutant concentrations using geospatial techniques, there are few shortcomings. We observe a lack of comprehensive analysis of crossvalidation and the need to increase the scale to obtain higher resolution predictions. Some of the relevant works are summarized in Table 1. The specific use of these techniques is not done in Delhi, where the geographical distance between sites was small yet monitoring gaps existed. The use of these techniques overrules the need for other boundary conditions apart from the geographical coordinates and measured concentrations. In order to fill these monitoring gaps, 
the objective of this work is to obtain reliable predictions of important, yet unmonitored sites. The quality and the interrelation of the considered datasets played an important role in determining the accuracy and the efficiency of predictions. However, considering the scope of the study and future applicability, the results are encouraging. IDW and kriging used in this study can target three major challenges: (i) proxy $\mathrm{PM}_{2.5}$ developments in case of insufficient ambient air quality measurements station; (ii) imputation of inconsistent information on daily $\mathrm{PM}_{2.5}$ concentration; and (iii) identification of high and low $\mathrm{PM}_{2.5}$ hotspots and episodes.

Table 1 here

\section{Study Area}

Delhi, the capital of India, is a second most populated city of India, narrowly surpassing Mumbai (World population review, 2019) in the north of the country. New Delhi is one of the urban districts of Delhi and the seat of all three branches of Government. There has been rapid urbanization and a corresponding increase in traffic and energy consumption. Moreover, there has been growing evidence that ambient $\mathrm{PM}_{2.5}$ levels of are observed to be highest in Delhi (Shukla et al., 2018; Gupta et al., 2007), and the concentrations have even touched $999 \mu \mathrm{g} / \mathrm{m}^{3}$ in the worst months (Mukherjee et al., 2018). The vehicle count has exhibited a surge in the last decade which leads to an increased vehicular density. This contributes to higher pollutant concentrations apart from other problems (Panwar et al., 2018). Considering the significance this city holds in terms of the economic, cultural and industrial growth along with being the international gateway to the world, it is crucial to ascertain the sustainability of the city in terms of infrastructure and the massive population it resides.

The temperature of the city rises to as high as $45^{\circ} \mathrm{C}$, in the summer months of April to June, whereas it falls to the lowest of $8^{\circ} \mathrm{C}$ in the winter months of December to January. The annual average temperature is $25 \pm 7^{\circ} \mathrm{C}$ for the study duration of 2015 to 2017 . The monitoring stations and target locations (where predictions for $\mathrm{PM}_{2.5}$ are made) are shown in Figure 1. Location coordinates are superimposed on a shape-file of Delhi in ArcGIS (version 10.2).

Figure 1 here

Majority of the monitoring stations are maintained by the Central Pollution Control Board (CPCB), Delhi Pollution Control Committee (DPCC) and the Indian Institute of Tropical Metrology (IITM), Pune. Monitoring data is accessible to both public/institutional bodies and 
individuals. However, there is a lack of a comprehensive network of monitoring stations, which are sometimes not practical to maintain.

\section{Site Selection and Characteristics}

Among 36 monitoring stations located within Delhi, only 17 monitored $\mathrm{PM}_{2.5}$ concentrations for the study period of January 2015 to December 2016 and November 2017 to February 2018. This highlights the need to use modelling-based prediction techniques to get dependable concentration estimates for these and other sites. Traffic and industrial hotspots, dense residential areas and other areas of maximum exposure were considered in ascertaining the target locations (Yedla and Shrestha, 2003). The residential zones listed face the huge magnitude of traffic flow daily. Hence $\mathrm{PM}_{2.5}$ becomes a significant cause of concern (Pandey et al., 2005). Institutional areas, which are away from the industrial areas, though devoid of most pollutants, still have large exposure to $\mathrm{PM}_{2.5}$ (Brunekreef and Forsberg, 2005). These sites are listed in table 2, along with the characteristics.

The sites under study lie in Delhi, which is a major hotspot of industrial and economic significance for the country and holds a prominent place globally as well (Desai and Vanneman, 2018). Although, the methods are simple, they provide a reliable estimate of $\mathrm{PM}_{2.5}$ concentrations at few target sites of significant importance, where instrumental monitoring is not feasible due to logistic or financial constraints. The city under study is host to a large population which is residing in relatively smaller area, contributing to high population density. Air pollution, especially particulate matter is threatening the sustainability of the city and posing a potential hazard to the significant population size. Working in synergy with other contributors, robust input about the estimate of this perilous pollutant, can ascertain the sustainability of the city and adjoining satellite towns (Bikkina et al., 2019).

Delhi exhibits a mixed land use pattern, making the traffic density higher and increasing the exposure to synergic air pollutants (Kumar et al., 2015). $\mathrm{PM}_{2.5}$ has a high potential to affect the people living in areas shared by various other types of land use (Mohan et al., 2011)

Table 2 here 
The scope of the study is not expanded to monitoring sites of NCR, due to possible error formation from long-range extrapolation. The distance between monitoring sites of Delhi and locations of NCR is very high as compared to the inter-site distance inside Delhi itself. The identified monitoring stations undertake 24-hour monitoring in 3 batches of 8-hours samples for $\mathrm{PM}_{2.5}$. Due care is taken to ensure that the standard guidelines are followed while monitoring and data inventory as $\mathrm{CPCB}$ is the authority to ascertain the guidelines. Additionally, the data were screened for any discrepancies of negative or zero concentrations along with certain unexplained spikes in the concentration, attributing them to monitoring errors.

$\mathrm{PM}_{2.5}$ concentrations are adopted from above-mentioned monitoring stations for two-phase durations: 24 months' data from 4 sites, and 4 months' data from 17 sites. Some data discrepancies have been observed, as noted in Table 2. The highest $\mathrm{PM}_{2.5}$ concentrations among adopted 24-month data are documented at Anand Vihar monitoring station in January 2016 (i.e. $\left.329 \mu \mathrm{g} / \mathrm{m}^{3}\right)$, whereas the lowest value $\left(28 \mu \mathrm{g} / \mathrm{m}^{3}\right)$ is recorded at Mandir Marg for the month of July 2016. The time series of $\mathrm{PM}_{2.5}$ datasets from January 2015 till December 2016 is presented in Figure 2. Furthermore, Figure 3 shows the recorded levels of $\mathrm{PM}_{2.5}$ from November 2017 till February 2018 under three site categories.

Figure 2 here

For the 4 months' data, the peak is observed at Anand Vihar, during the month of November 2017 (i.e. $330 \mu \mathrm{g} / \mathrm{m}^{3}$ ). On the other hand, the lowest value is exhibited by Lodhi Road at 90 $\mu \mathrm{g} / \mathrm{m}^{3}$ for the month of February 2018.

Figure 3 here

Interpolation and Cross-Validation

A better database of pollutant data can be compiled if a spatial point estimation process is developed, although, there exists no best method to interpolate any data set. Some criteria to 
choose among the available methods could be the accuracy level required, characteristics of the data available and the computer/human resources at disposal (Lin et al., 2002).

Current work applies two spatial interpolation techniques: Kriging, which is a stochastic method; and Inverse Distance Weighting (IDW), which is a deterministic interpolation method. Apart from the statistical and deterministic techniques, LUR and dispersion modelling are also used extensively to make air pollution predictions. Both of the modelling techniques have already been researched on both local and regional scales. Another interpolation technique available in ArcGIS is a spline function. It was not used for the study as it is better for datasets which exhibit mild variability, but we observe high seasonal variability in $\mathrm{PM}_{2.5}$ concentrations. Since different techniques yield different variations for the same data set, multiple methods need to be studied with regarding their surface analysis. Kriging is a geostatistical process, which defines a correlation (semivariogram) among the sample points; it is used to model the spatial variation in the pollutant concentration. Application of the methods for Delhi $\mathrm{PM}_{2.5}$ concentrations have been carried out due to two reasons. Firstly, it is a variable which is spatially distributed and secondly, it appears to be correlated across well-defined geographical regions (Jerrett et al., 2005). Base data for geospatial analysis is the monthly average data, obtained from 24-hour daily averages for $\mathrm{PM}_{2.5}$ from NAAQMs stations in Delhi. These stations provide hourly, 8 hourly and 24 hourly averages of various air pollutants along with values of temperatures and other meteorological parameters. The 24-hour average of $\mathrm{PM}_{2.5}$ at the stations were obtained from the stations and converted to monthly averages after filtering out zero and negative values attributed to measurement and instrumentation error.

We used a tool "geostatistical analyst" in ArcGIS to analyse spatially varying data inventory and generation of the two-dimensional surface using measured data while employing advanced statistical techniques. Spatial interpolation provides us with the best representation for a surface and helps in predicting the required values of unmonitored sampling points to create a comprehendible surface (Johnston et al., 2003). Spatio-temporal analysis of the pollutant helps to make informed policy changes and to concentrate mitigation efforts at critical locations which can be identified (Boiné et al., 2018)

\section{Inverse Distance Weighting}

IDW interpolation explicitly works on the assumption that things which are closer to each other are more alike than those which are farther apart. Greater weight will be assigned to the points 
which are closest to the target location, and hence the allocated weights change as an inverse function of ' $p^{\text {th }}$ power of distance', where power function $(p)$ is a positive real number. Greater values of $\mathrm{p}$ grant greater influence on values which are closest to the point to be interpolated. The parameter prediction for the target location is a summation of the product of 'allotted weights' and 'measured values' for all sites. After reviewing numerous literature, $p$ is taken to be 2 for the current study.

Kriging - Ordinary

Kriging offers some advantages over other interpolation techniques. It interpolates using weights independent of the data, hence practically, the weighs after the first estimation can be used for all data sets. Also, it is an 'exact' interpolator i.e., estimate at any observational point is the observation itself (Zimmerman and Homer, 1991).

Kriging has a smoothening effect on the result where it overestimates the higher values and underestimates the lower values. Since the data has a smooth trend with lesser daily fluctuations, this was not a cause of concern in the study.

The necessary steps to predict with Kriging are uncovering the rule for getting the dependence and making estimations. The most significant contribution of Kriging based dependence estimation is the effect of 'statistical stationarity' in few cases of predicting values. Some data sets are observed to be random to the extent of contributing to a situation, in which the prediction methodology fails to establish any correlation to carry out dependable estimation. This is termed as a condition of 'pure nugget effect' which was observed in the months of June, July and December of 2015, and February to June of 2016. One month's variogram, where estimation failed because of pure nugget effect, is shown in Figure 4(b).

Other prediction techniques fail to identify this situation and lead to highly inaccurate estimations. Variograms and covariance functions are created to predict the required relationship called the statistical dependence (and called spatial autocorrelation). A sample variogram for the month of December 2017 is shown in Figure 4(a).

Statistical Stationarity and the Nugget Effect 
Statistical Stationarity considers the total set of observed data points as a single variable series. Additionally, a system of repetition must be realized to develop any kind of deduction procedures; and if not present, created. Nugget effect refers to the discontinuity towards the origin of the semivariogram. This discontinuity is reported to be caused by measurement errors and micro-variability in the spatial phenomenon being considered (Howarth, 1978). In the current study, due to the 'absence' of statistical stationarity in the data set, 'pure nugget effect' was observed. Kriging failed in predicting the required values for June, July and December of 2015, and February to June of 2016. One month's variogram, where Kriging failed because of pure nugget effect, is shown in Figure 4(b).

Figure 4 here

Cross-validation of concentration measured at monitoring sites

For cross-validation, recorded $\mathrm{PM}_{2.5}$ concentrations from 3 monitoring stations are used to predict the value at the 4 th site. This is then compared with the measured value at the 4 th site, to obtain a percentage error. These errors give an estimate as to how well has the semivariogram been fitted over the plotted data points, and how dependable the predictions will be. Figures 5(a) and 5(b) represent the error between measured and predicted values at 4 monitoring sites (for 24-month $\mathrm{PM}_{2.5}$ data) and 17 monitoring sites (for 4-month $\mathrm{PM}_{2.5}$ data), respectively.

$\mathrm{PM}_{2.5}$ concentrations have been mapped and estimated using Kriging and IDW techniques in multiple studies (Xie et al., 2017) and they are authentic prediction techniques as per credible references ( $\mathrm{Wu}$ et al., 2018). Whereas, superior modelling development requires extensive work on the development which would reduce the scale of the current study and divert the purpose of the study towards a development-centric modelling criteria (de Hoogh et al., 2018). The major goal of the study had been to provide a comprehensive, ready-to-use mapped and predictive estimate of $\mathrm{PM}_{2.5}$ blanket over the city. Inclusion of various metrological factors along with 3D building information and land use analysis would further require feasibility studies, which can be an interesting study area for research in future, although, for the immediate requirement of $\mathrm{PM}_{2.5}$ estimates at indispensable sites of Delhi, this holds less relevance as the land use and topography is homogeneous (Ahmad et al., 2016) 
Figure 5 here

\section{Results and Discussions}

Predictions based on 2-year data

Predictions were made at two locations: IIT Delhi campus and Central Park, Connaught Place using $\mathrm{PM}_{2.5}$ concentration data for each month from the period January 2015 to December 2016 from 4 monitoring stations (Anand Vihar, Punjabi Bagh, Mandir Marg and R K Puram). Both IDW and Kriging predictions were archived for the two locations, and the predicted concentrations are plotted against each other as shown in Figure 6.

Figure 6 here

The predictions at IIT Delhi showed a peak $\left(274 \mu \mathrm{g} / \mathrm{m}^{3}\right)$ in November 2016 using the IDW technique. On the other hand, the lowest value $\left(41 \mu \mathrm{g} / \mathrm{m}^{3}\right)$ is exhibited during August 2016 at using the same technique. Moreover, the peak prediction for Connaught Place is noted to be $271 \mu \mathrm{g} / \mathrm{m}^{3}$ during November 2016 using Kriging, while the lowest value $\left(31 \mu \mathrm{g} / \mathrm{m}^{3}\right)$ is exhibited for July 2016 at Connaught Place using the IDW technique.

Predictions based on 4 months' data

Figure 7 here

Figure 7 shows the predictions using four-month $\mathrm{PM}_{2.5}$ data from multiple monitoring stations. The IDW technique on the 4-months data for Residential and Institutional prediction locations showed the peak $\left(305 \mu \mathrm{g} / \mathrm{m}^{3}\right)$ in November 2017 (i.e. at Rithala) as opposed to lowest values $\left(114 \mu \mathrm{g} / \mathrm{m}^{3}\right)$ for the month of February 2018 at Shahdara. When it was used for Industrial, Transport and Commercial prediction locations, the peak $\left(216 \mu \mathrm{g} / \mathrm{m}^{3}\right)$ is again observed in November 2017 (i.e. at Peeragarhi) while the lowest value $\left(116 \mu \mathrm{g} / \mathrm{m}^{3}\right)$ is exhibited in February 2018 at ISBT Kashmere Gate. 
When the Kriging technique was used for $\mathrm{PM}_{2.5}$ prediction using the 4 months' data for Residential and Institutional prediction locations, the peak $\left(267 \mu \mathrm{g} / \mathrm{m}^{3}\right)$ is observed in November 2017 i.e. at Rithala. On the other hand, the lowest value $\left(116 \mu \mathrm{g} / \mathrm{m}^{3}\right)$ is exhibited for the month of February 2018 at Shahdara. When it was used for Industrial, Transport and Commercial prediction locations, the peak $\left(263 \mu \mathrm{g} / \mathrm{m}^{3}\right.$ at Peeragarhi) are again observed in November 2017 while the lowest value $\left(122 \mu \mathrm{g} / \mathrm{m}^{3}\right)$ is exhibited for the month of January 2018 at, at AIIMS. The process of cross-validation is available in the geostatistical analyst of ArcGIS. The effectiveness of the fitted semivariogram is the measure of how accurate the predictions would be. The plotted percentage errors in Figures 5a,b show how well the semivariogram had fit. It also gives an estimate of how dependable the predicted values using these semivariogram would be.

Predicted surfaces

Figure 8 here

Figure 8a shows the predicted surfaces for the first phase i.e. November 2017 to February 2018 and in figures 8 (b) and 8 (c) for January 2015 to December 2016. The trend observed in the predicted value is like the trend observed in the monitored values, apart from the variation in magnitude.

Kriging exhibits failure for the months of June, July and December for 2015 and February to June for the year of 2016. IDW proves to be effective in predicting the values for these months. IDW is more efficient in identifying pollution hotspots from the mapped prediction surfaces. Kriging tends to have a 'smoothening' effect. But Kriging is more effective in predictions when the number of input points are higher and spatial orientation is important. This is noted in phase II of the study when $\mathrm{PM}_{2.5}$ data from 17 monitoring stations were used. Similar effects have been observed in a study of Arsenic contaminated soil samples (Qiao et al., 2018). For applications related to health impact assessments, the use of hybrid methods that combine air quality model outputs with observational data is suggested to obtain effective results. A largescale study has been conducted in the Atlanta region of Georgia which compares various techniques and explore the said hybrid models (Yu et al., 2018). In a case when multiple pollutants are selected, for instance, $\mathrm{PM}_{10}$ and $\mathrm{PM}_{2.5}$, Kriging seems to perform better with 
$\mathrm{PM}_{10}$ and IDW is more suitable for $\mathrm{PM}_{2.5}$. A recent study (Lin et al., 2018) conducted in Shanghai, China, reported similar results. Other studies have established that increasing the geographical area under consideration causes the predicted values to be unreliable as the distance between monitored sites and target sites increases, leading to uncertainties. The uncertainties are pertaining to inaccuracies in predictions as percentage error in crossvalidation increase significantly. Considering one of the recent studies (Xu et al., 2019), the error analysis of predicted results indicates that as the distance increases, reliability reduces. Recently, Qiao et al (2018) compared Ordinary kriging with IDW while studying soil pollution in China and identified better prediction accuracy for IDW. Like this study, other techniques (Kriging based) were used where Ordinary Kriging failed to predict maximum and minimum concentrations.

As per the extensive study of the past researches on $\mathrm{PM}_{2.5}$ using Kriging and IDW, the variation in error percentage is subject to the geographical location of the site and their relative position with respect to each other and with the target location at which the value needs to be estimated. Larger grid sizes and therefore larger effective distances between sites of concern leads to higher errors in predictions (Alexeeff et al., 2015). Higher resolution studies cause the effective distance between sites and the variation in concentrations to reduce leading to more accurate predictions (Hu et al., 2019)

Another recent study in Madrid, Spain (Gómez-Losada et al., 2019) observed the effect of Urban Heat Island on the predicted pollutant values. Delhi is also known to be affected by the same phenomenon and hence the higher percentage errors in predictions for the summer months can be attributed to this. Additionally, the effect of wind speed on the predicted values has been studied in the Kocaeli region of Turkey (Erener et al., 2018). Adding the effect of wind speed to future studies would give better results. $\mathrm{PM}_{2.5}$ also affects the indoor air quality in places which are densely populated and residential zones are located closer to traffic and highways (Martins and da Graça 2018). Modelling techniques have been used to predict the effect of outdoor air quality on the indoor air quality highlighting the effect (Karri et al., 2018). Prediction of pollutant concentration using Kriging and IDW techniques has acceptable dependability and the future scope of combining it with other spatial interpolation techniques is vast. If metrological and physical influences can be combined with the raw prediction results from Kriging and IDW, the reliability of the predictions shall increase manifold. These 
techniques can be applied without the boundary conditions of having a grid which makes them versatile and usable for cases where the monitoring sites are scattered.

Improved interpolation techniques beyond simple Kriging and IDW have been developed as Probability Kriging, Disjunctive Kriging and Empirical Bayesian Kriging which are used for other applications, apart from air pollution prediction. Moreover, hybrid techniques have been developed which incorporates spatial interpolation technique (Kriging) and regression analysis that can produce a detailed prediction map with improved accuracy and prediction dependability (Yao et al., 2013). Yet, combining the two spatial interpolation techniques would require reprogramming of the techniques, validation of which can be studied through future studies. Therefore, apart from their aid to interpret results, combining them into a hybrid technique is beyond the scope of the current study, but can certainly make an interesting area of interest for future research.

There is a possibility of reducing the temporal scale of the study to daily and even hourly concentrations by integrated advanced computer programming. Further work towards ascertaining the statistical stationarity of the data without going through the Kriging process could provide an added advantage. This would lead to realising that the method has failed for the data set at hand at the semivariogram stage only. In turn, if the datasets were to be segregated while using other prediction techniques such as IDW (if required), both man hours and computational power can be reduced.

Figure 8 here

$\mathrm{PM}_{2.5}$ mapping methods used in this study can act as a baseline for various hotspots within the city, which are growing at an appreciable rate in terms of the population of people and road vehicles as well as the need for the total energy (Shukla et al., 2018; Kumar et al., 2013; Gulia et al., 2017) The mapped pollutant profile of concentrations can ensure that the policy changes and future town planning provisions are in accordance with the goal of mitigating the pollutant concentrations (Chowdhury et al., 2019).

\section{Summary and Conclusions}

$\mathrm{PM}_{2.5}$ is the major contributors to the health, transport and infrastructural challenges faced by the city. The study has utilised monitored concentrations of $\mathrm{PM}_{2.5}$ at various monitoring stations across the city of Delhi to predict corresponding values at other sites of interest in the city. We used two methods of interpolation: a deterministic technique namely Inverse Distance 
Weighting and a statistical method namely Kriging. Cross-validation analysis concluded that 24-month $\mathrm{PM}_{2.5}$ concentrations exhibit errors of the magnitude as $19 \%$ and $17 \%$ for 2015 , and $27 \%$ and $26 \%$ for 2016, for IDW and Kriging, respectively. Additionally, in phase II, when 17 monitoring stations were included in the study by using 4-month data (November 2017 to February 2018). $\mathrm{PM}_{2.5}$ concentrations predictions yielded an average error percentage of $23 \%$ by both IDW and Kriging individually. Thus, it is challenging to conclude one of the two methods better, although, for the gaps, where Kriging fails to interpolate due to the absence of data stationarity, IDW fills in well.

Within the scope of this work, there was no procedure to ascertain the verification of statistical stationarity, hence some of the results from the Kriging technique are omitted. The prediction, in this case, results in constant value over the whole of the predicted surface. Kriging is unable to interpolate data that is not statistically stationary. To ascertain the statistical stationarity of the data beforehand is a tedious process which is itself an emerging research topic and requires extensive use of high-level computing tools. The formulated $\mathrm{PM}_{2.5}$ thematic maps can eventually provide a basis for efficient actions to control air pollution and further handle various societal and technological challenges.

\section{Funding and Acknowledgements}

This work has been supported by the University grant commission - Junior Research Fellowship, India, and also the Natural Environmental Research Council [grant number NE/P016510/1] through the project - An Integrated Study of Air Pollutant Sources in the Delhi National Capital Region (ASAP-Delhi) - under the UK-India NERC-MOES Programme on Air Quality and Health in Megacity Delhi.

\section{References}

Ahmad, N., Ahsan, N., \& Said, S. (2019). Land use Mapping of Yamuna river Flood Plain in Delhi using K-Mean and spectral angle image classification algorithms. Water and Energy International, 62(5), 63-68.

Alexeeff, S. E., Schwartz, J., Kloog, I., Chudnovsky, A., Koutrakis, P., \& Coull, B. A. (2015). Consequences of kriging and land use regression for PM2. 5 predictions in epidemiologic analyses: insights into spatial variability using high-resolution satellite data. Journal of Exposure Science and Environmental Epidemiology, 25(2), 138. 
Awasthi, A., Agarwal, R., Mittal, S. K., Singh, N., Singh, K., \& Gupta, P. K. (2011). Study of size and mass distribution of particulate matter due to crop residue burning with seasonal variation in rural area of Punjab, India. Journal of Environmental Monitoring, 13(4), 10731081.

Baklanov, A., Korsholm, U., Mahura, A., Petersen, C., \& Gross, A. (2008). ENVIROHIRLAM: on-line coupled modelling of urban meteorology and air pollution. Advances in Science and Research, 2(1), 41-46.

Bikkina, S., Andersson, A., Kirillova, E. N., Holmstrand, H., Tiwari, S., Srivastava, A. K., ... \& Gustafsson, Ö. (2019). Air quality in megacity Delhi affected by countryside biomass burning. Nature Sustainability, 2(3), 200.

Boiné, K., Demers, C. M., \& Potvin, A. (2018). Spatio-temporal promenades as representations of urban atmospheres. Sustainable Cities and Society, 42, 674-687.

Boznar, M., Lesjak, M., \& Mlakar, P. (1993). A neural network-based method for short-term predictions of ambient $\mathrm{SO} 2$ concentrations in highly polluted industrial areas of complex terrain. Atmospheric Environment. Part B. Urban Atmosphere, 27(2), 221-230..

Brunekreef, B., \& Forsberg, B. (2005). Epidemiological evidence of effects of coarse airborne particles on health. European respiratory journal, 26(2), 309-318.

Chowdhury, S., Dey, S., Guttikunda, S., Pillarisetti, A., Smith, K. R., \& Di Girolamo, L. (2019). Indian annual ambient air quality standard is achievable by completely mitigating emissions from household sources. Proceedings of the National Academy of Sciences, 116(22), 10711-10716.

Chung, U., \& Yun, J. I. (2004).Solar irradiance-corrected spatial interpolation of hourly temperature in complex terrain.Agricultural and forest meteorology, 126(1-2), 129-139.

Chung, K. F., Zhang, J., \& Zhong, N. (2011). Outdoor air pollution and respiratory health in Asia. Respirology, 16(7), 1023-1026.

Cohen, A. J., Brauer, M., Burnett, R., Anderson, H. R., Frostad, J., Estep, K., ... \& Feigin, V. (2017). Estimates and 25-year trends of the global burden of disease attributable to ambient air pollution: an analysis of data from the Global Burden of Diseases Study 2015. The Lancet, 389(10082), 1907-1918. 
CPCB. (2018). Guidelines for continuous emission monitoring systems (Revision 1), Central Pollution Control Board, Government of India, New Delhi, India.

de Hoogh, K., Strak, M., Chen, J., Gulliver, J., Hertel, O., Brunekreef, B., \& Hoek, G. (2018). OP III-2 Air pollution exposure assessment for the elapse project using hybrid lur models.

Desai, S., \& Vanneman, R. (2018). National Council of Applied Economic Research, New Delhi. India Human Development Survey (IHDS), 2005. Ann Arbor, MI: Inter-university Consortium for Political and Social Research [distributor], 08-08.

Dünnebeil, G., Marjanović, M., \&Žarko, I. P. (2017, May).Approaches to Fuse Fixed and Mobile Air Quality Sensors.In International Symposium on Environmental Software Systems (pp. 71-84).Springer, Cham.

Erener, A., Sarp, G., \& Yıldırım, Ö. (2019). Seasonal Air Pollution Investigation and Relation Analysis of Air Pollution Parameters to Meteorological Data (Kocaeli/Turkey). In Advances in Remote Sensing and Geo Informatics Applications (pp. 355-358). Springer, Cham.

Fotourehchi, Z. (2016). Health effects of air pollution: An empirical analysis for developing countries. Atmospheric Pollution Research, 7(1), 201-206.

Giustini, F., Ciotoli, G., Rinaldini, A., Ruggiero, L., \& Voltaggio, M. (2019). Mapping the geogenic radon potential and radon risk by using Empirical Bayesian Kriging regression: A case study from a volcanic area of central Italy. Science of The Total Environment, 661, 449464.

Gómez-Losada, Á., Santos, F. M., Gibert, K., \& Pires, J. C. (2019). A data science approach for spatiotemporal modelling of low and resident air pollution in Madrid (Spain): Implications for epidemiological studies. Computers, Environment and Urban Systems, 75, 1-11.

Greenstone, M., \& Hanna, R. (2014). Environmental regulations, air and water pollution, and infant mortality in India. American Economic Review, 104(10), 3038-72.

Gulia, S., Nagendra, S. S., \& Khare, M. (2017). A system based approach to develop hybrid model predicting extreme urban NOx and PM2. 5 concentrations. Transportation Research Part D: Transport and Environment, 56, 141-154.

Gupta, P. K., Singh, K., Dixit, C. K., Singh, N., Sharma, C., Sahai, S., ... \& Garg, S. C. (2007). Spatial distribution in aerosol mass and size characteristics between Delhi and Hyderabad during land campaign in February 2004. 
Heal, M.R., Kumar, P., Harrison, R.M., 2012. Particles, air quality, policy and health. Chemical Society Reviews 41, 6606-6630

Howarth, R. (1978). (M.) Guarascio, (M.) David, and (C.) Huijbregts, editors. Advanced Geostatistics in the Mining Industry. Dordrecht, Holland (D. Reidel Publishing Co.), 1976. xvi 461 pp., 126 figs. Price Dfl. 105.00 (\$39.50). Mineralogical Magazine, 42(322), 302-303. doi:10.1180/minmag.1978.042.322.35

Hu, H., Hu, Z., Zhong, K., Xu, J., Zhang, F., Zhao, Y., \& Wu, P. (2019). Satellite-based highresolution mapping of ground-level PM2. 5 concentrations over East China using a spatiotemporal regression kriging model. Science of The Total Environment, 672, 479-490.

Hurley, P. J., Physick, W. L., \& Luhar, A. K. (2005). TAPM: a practical approach to prognostic meteorological and air pollution modelling. Environmental Modelling \& Software, 20(6), 737 752.

Jerrett, M., Arain, A., Kanaroglou, P., Beckerman, B., Potoglou, D., Sahsuvaroglu, T., ... \& Giovis, C. (2005). A review and evaluation of intraurban air pollution exposure models. Journal of Exposure Science and Environmental Epidemiology, 15(2), 185.

Johnston, K., Ver Hoef, J. M., Krivoruchko, K., \& Lucas, N. (2001). Using ArcGIS geostatistical analyst (Vol. 380). Redlands: Esri.

Kanada, M., Dong, L., Fujita, T., Fujii, M., Inoue, T., Hirano, Y., ... \& Geng, Y. (2013). Regional disparity and cost-effective SO2 pollution control in China: A case study in 5 megacities. Energy policy, 61, 1322-1331.

Kandlikar, M., \& Ramachandran, G. (2000). The causes and consequences of particulate air pollution in urban India: a synthesis of the science. Annual review of energy and the environment, 25(1), 629-684.

Kandlikar, M., \& Ramachandran, G. (2000). The causes and consequences of particulate air pollution in urban India: a synthesis of the science. Annual review of Energy and the Environment, 25(1), 629-684.

Karri, R. R., Heibati, B., Yusup, Y., Rafatullah, M., Mohammadyan, M., \& Sahu, J. N. (2018). Modeling airborne indoor and outdoor particulate matter using genetic programming. Sustainable Cities and Society, 43, 395-405. 
Kumar, P., Gulia, S., Harrison, R. M., \& Khare, M. (2017). The influence of odd-even car trial on fine and coarse particles in Delhi. Environmental Pollution, 225, 20-30.

Kumar, P., Jain, S., Gurjar, B. R., Sharma, P., Khare, M., Morawska, L., \& Britter, R. (2013). New directions: can a "blue sky" return to Indian megacities?. Atmospheric Environment, 71, 198-201.

Kumar, P., Khare, M., Harrison, R. M., Bloss, W. J., Lewis, A., Coe, H., \& Morawska, L. (2015). New directions: air pollution challenges for developing megacities like Delhi. Atmospheric Environment, 122, 657-661.

Kumari, M., Basistha, A., Bakimchandra, O., \& Singh, C. K. (2016).Comparison of spatial interpolation methods for mapping rainfall in Indian Himalayas of Uttarakhand region. In Geostatistical and Geospatial Approaches for the Characterization of Natural Resources in the Environment (pp. 159-168). Springer, Cham.

Kumar, P., Patton, A.P., Durant, J.L., Frey, H.C., 2018. A review of factors impacting exposure to $\underline{\mathrm{PM}}_{2.5}$, ultrafine particles and black carbon in Asian transport microenvironments. Atmospheric Environment 187, 301-316.

Lelièvre, N., Beaurepaire, P., Mattrand, C., \& Gayton, N. (2018). AK-MCSi: a Kriging-based method to deal with small failure probabilities and time-consuming models. Structural Safety, 73, 1-11.

Lin, J., Zhang, A., Chen, W., \& Lin, M. (2018). Estimates of Daily PM2. 5 Exposure in Beijing Using Spatio-Temporal Kriging Model. Sustainability, 10(8), 2772.

Lin, Z. H., Mo, X. G., Li, H. X., \& Li, H. B. (2002). Comparison of three spatial interpolation methods for climate variables in China. Acta Geographica Sinica, 1, 47-56.

Mallet, V., \& Sportisse, B. (2008). Air quality modeling: From deterministic to stochastic approaches. Computers \& Mathematics with Applications, 55(10), 2329-2337.

Martins, N. R., \& da Graça, G. C. (2018). Impact of PM2. 5 in indoor urban environments: A review. Sustainable Cities and Society, 42, 259-275.

Mohan, M., Pathan, S. K., Narendrareddy, K., Kandya, A., \& Pandey, S. (2011). Dynamics of urbanization and its impact on land-use/land-cover: a case study of megacity Delhi. Journal of Environmental Protection, 2(09), 1274. 
Mukherjee, T., Asutosh, A., Pandey, S. K., Yang, L., Gogoi, P. P., Panwar, A., \& Vinoj, V. (2018). Increasing potential for air pollution over megacity new delhi: A study based on 2016 diwali episode. Aerosol and Air Quality Research, 18(9), 2510-2518.

Nagpure, A. S., Gurjar, B. R., Kumar, V., \& Kumar, P. (2016). Estimation of exhaust and nonexhaust gaseous, particulate matter and air toxics emissions from on-road vehicles in Delhi. Atmospheric environment, 127, 118-124.

Palomino, I., \& Martin, F. (1995). A simple method for spatial interpolation of the wind in complex terrain. Journal of Applied Meteorology, 34(7), 1678-1693.

Pandey, J. S., Kumar, R., \& Devotta, S. (2005). Health risks of NO2, SPM and SO2 in Delhi (India). Atmospheric Environment, 39(36), 6868-6874.

Panwar, M., Agarwal, A., \& Devadas, V. (2018). Analyzing land surface temperature trends using non-parametric approach: A case of Delhi, India. Urban climate, 24, 19-25.

Park, N. W. (2016). Time-series mapping of PM10 concentration using multi-gaussian spacetime kriging: a case study in the Seoul metropolitan area, Korea. Advances in Meteorology, 2016.

Qi, Z., Wang, T., Song, G., Hu, W., Li, X., \& Zhang, Z. (2018). Deep air learning:

Interpolation, prediction, and feature analysis of fine-grained air quality. IEEE Transactions on Knowledge and Data Engineering, 30(12), 2285-2297.

Qiao, P., Lei, M., Yang, S., Yang, J., Guo, G., \& Zhou, X. (2018). Comparing ordinary kriging and inverse distance weighting for soil as pollution in Beijing. Environmental Science and Pollution Research, 25(16), 15597-15608.

Rosencranz, A., \& Jackson, M. (2003). The Delhi pollution case: the Supreme Court of India and the limits of judicial power. Colum. J. Envtl. L., 28, 223.

Rossi, L., Calizza, E., Careddu, G., Rossi, D., Orlandi, L., Jona-Lasinio, G., ... \& Costantini, M. L. (2018). Space-time monitoring of coastal pollution in the Gulf of Gaeta, Italy, using $\delta 15 \mathrm{~N}$ values of Ulva lactuca, landscape hydromorphology, and Bayesian Kriging modelling. Marine pollution bulletin, 126, 479-487.

Shukla, K., Srivastava, P. K., Banerjee, T., \& Aneja, V. P. (2017). Trend and variability of atmospheric ozone over middle Indo-Gangetic Plain: impacts of seasonality and precursor gases. Environmental Science and Pollution Research, 24(1), 164-179. DOI: 10.1007/s11356- 
Shukla, K., Ojha, N., \& Khare, M., (2018) Air Quality Simulations over Delhi Using WRF-Chem in Conference of Indian Aerosol Science and Technology Association 2018 "Aerosol Impacts: Human Health to Climate Change"2018 http://cas.iitd.ac.in/iasta2018/pdf/EProceedings_IASTA-2018.pdf

Silva, B. N., Khan, M., \& Han, K. (2018). Towards sustainable smart cities: A review of trends, architectures, components, and open challenges in smart cities. Sustainable Cities and Society, $38,697-713$.

Silva, L. T., \& Mendes, J. F. (2012). City Noise-Air: An environmental quality index for cities. Sustainable Cities and Society, 4, 1-11.

Srinivasan, J., \& Gadgil, S. (2002). On the Asian brown cloud controversy. Current Science, 83(11), 1307-1309.

Vorapracha, P., Phonprasert, P., Khanaruksombat, S., \&Pijarn, N. (2015).A comparison of Spatial Interpolation Methods for predicting concentrations of Particle Pollution (PM10). International Journal of Chemical, Environmental and Biological Sciences, 3(4), 302-306.

Wong, F. T., Sulistio, A., \& Syamsoeyadi, H. (2018). Kriging-Based Timoshenko Beam Elements with the Discrete Shear Gap Technique. International Journal of Computational Methods, 15(07), 1850064.

World Health Organization. (2016). Ambient air pollution: A global assessment of exposure and burden of disease.

World population review (2019). Total Population by Country 2018 retrieved from http://worldpopulationreview.com/countries/india- of the date 21st January, 2019

Wu, M., Huang, J., Liu, N., Ma, R., Wang, Y., \& Zhang, L. (2018, November). A Hybrid Air Pollution Reconstruction by Adaptive Interpolation Method. In Proceedings of the 16th ACM Conference on Embedded Networked Sensor Systems (pp. 408-409). ACM.

Xie, X., Semanjski, I., Gautama, S., Tsiligianni, E., Deligiannis, N., Rajan, R., ... \& Philips, W. (2017). A review of urban air pollution monitoring and exposure assessment methods. ISPRS International Journal of Geo-Information, 6(12), 389.

Xu, H., Bechle, M. J., Wang, M., Szpiro, A. A., Vedal, S., Bai, Y., \& Marshall, J. D. (2019). National PM2. 5 and NO2 exposure models for China based on land use regression, satellite measurements, and universal kriging. Science of the Total Environment, 655, 423-433. 
Yao, X., Fu, B., Lü, Y., Sun, F., Wang, S., \& Liu, M. (2013). Comparison of four spatial interpolation methods for estimating soil moisture in a complex terrain catchment. PloS one, 8(1), e54660.

Yedla, S., \& Shrestha, R. M. (2003). Multi-criteria approach for the selection of alternative options for environmentally sustainable transport system in Delhi. Transportation Research Part A: Policy and Practice, 37(8), 717-729.

Yu, H., Russell, A., Mulholland, J., Odman, T., Hu, Y., Chang, H. H., \& Kumar, N. (2018). Cross-comparison and evaluation of air pollution field estimation methods. Atmospheric environment, 179, 49-60.

Zimmerman, D. L., \& Homer, K. E. (1991). A network design criterion for estimating selected attributes of the semivariogram. Environmetrics, 2(4), 425-441.

Table 1: Review of past studies on spatiotemporal analysis-based air pollutant prediction.

\begin{tabular}{|c|c|c|c|c|c|}
\hline Location & $\begin{array}{l}\text { Target } \\
\text { pollutant/ } \\
\text { parameters }\end{array}$ & Study focus & Major findings & Remarks & Reference \\
\hline China & $\begin{array}{l}\mathrm{PM}_{2.5} \\
\text { and } \mathrm{NO}_{2}\end{array}$ & $\begin{array}{l}\text { Regression- } \\
\text { based } \\
\text { improvement }\end{array}$ & $\begin{array}{l}\text { Universal } \\
\text { Kriging best }\end{array}$ & $\begin{array}{lr}\text { First } & \text { high- } \\
\text { resolution } & \text { LUR } \\
\text { models produced }\end{array}$ & $\begin{array}{l}\text { Xu et al. } \\
(2018)\end{array}$ \\
\hline $\begin{array}{l}\text { Beijing, } \\
\text { China }\end{array}$ & $\mathrm{PM}_{2.5}$ & $\begin{array}{l}\text { Comparison: } \\
\text { STK and } \\
\text { Kriging }\end{array}$ & $\begin{array}{l}\text { Fitting error of } \\
\text { Bilonick smallest }\end{array}$ & $\begin{array}{l}\text { Critical areas in } \\
\text { the north of the } \\
\text { study area. }\end{array}$ & $\begin{array}{l}\text { Lin et al. } \\
(2018)\end{array}$ \\
\hline $\begin{array}{l}\text { Western } \\
\text { Europe }\end{array}$ & $\begin{array}{l}\mathrm{PM}_{2.5}, \quad \mathrm{NO}_{2}, \\
\mathrm{O}_{3} \text { and } \mathrm{BC}\end{array}$ & $\begin{array}{l}100 \mathrm{~m} \times 100 \mathrm{~m} \\
\text { Hybrid models }\end{array}$ & $\begin{array}{l}\text { Improved } \\
\text { robustness }\end{array}$ & $\begin{array}{l}\text { Kriging } \\
\text { improves the } \\
\text { quality of LUR }\end{array}$ & $\begin{array}{l}\text { De Hoogh } \\
\text { et al. (2008) }\end{array}$ \\
\hline Spain & $\begin{array}{l}\text { Wind and } \\
\text { temperature }\end{array}$ & $\begin{array}{l}\text { AMDAR } \\
\text { improved }\end{array}$ & $\begin{array}{l}\text { Models } \\
\text { significant in } \\
\text { predictions }\end{array}$ & $\begin{array}{l}\text { Kriging proved } \\
\text { reliable }\end{array}$ & $\begin{array}{l}\text { Dalmau et } \\
\text { al. (2017) }\end{array}$ \\
\hline Morocco & $\begin{array}{l}\left(\mathrm{CH}_{4}\right),\left(\mathrm{CO}_{2}\right) \\
\text { and }\left(\mathrm{N}_{2} \mathrm{O}\right)\end{array}$ & $\begin{array}{l}\text { Prediction } \\
\text { using HPC }\end{array}$ & $\begin{array}{l}\text { Data processing } \\
\text { system used }\end{array}$ & $\begin{array}{l}\text { IASI instruments } \\
\text { used }\end{array}$ & $\begin{array}{l}\text { Albert et al. } \\
(2014)\end{array}$ \\
\hline $\begin{array}{l}\text { Los } \\
\text { Angeles, } \\
\text { CA, USA. }\end{array}$ & $\mathrm{NO}_{\mathrm{x}}$ & $\begin{array}{l}\text { LUR } \\
\text { Kriging } \\
\text { evaluated }\end{array}$ & $\begin{array}{l}\text { Kriging steadily } \\
\text { outperformed }\end{array}$ & $\begin{array}{l}\text { Ordinary } \\
\text { Kriging is a kind } \\
\text { of Universal } \\
\text { Kriging }\end{array}$ & $\begin{array}{l}\text { Mercer et } \\
\text { al. (2011) }\end{array}$ \\
\hline $\begin{array}{l}\text { Tehran, } \\
\text { Iran }\end{array}$ & $\mathrm{PM}_{10}$ & $\begin{array}{l}\text { Genetic } \\
\text { algorithms } \\
\text { (GAs) }\end{array}$ & $\begin{array}{l}\text { GAs reduce the } \\
\text { estimated error } \\
\text { significantly }\end{array}$ & $\begin{array}{l}\text { Kriging potent as } \\
\text { a prediction } \\
\text { technique }\end{array}$ & $\begin{array}{l}\text { Shad et al. } \\
(2009)\end{array}$ \\
\hline $\begin{array}{l}\text { Rome, } \\
\text { Italy }\end{array}$ & $\mathrm{NO}_{2}$ & $\begin{array}{l}\text { Land-use } \\
\text { regression }\end{array}$ & $\begin{array}{l}\text { Land-use } \\
\text { regression give } \\
\text { well-fitting } \\
\text { curves }\end{array}$ & $\begin{array}{l}\text { Emission data } \\
\text { did not bring } \\
\text { variation in } \mathrm{R}^{2}\end{array}$ & $\begin{array}{l}\text { Rosenlud et } \\
\text { al. (2008) }\end{array}$ \\
\hline $\begin{array}{l}\text { Hamilton, } \\
\text { Canada }\end{array}$ & $\mathrm{NO}_{2}$ & $\begin{array}{l}\text { Models } \\
\text { reviewed }\end{array}$ & $\begin{array}{l}\text { Hybrid class of } \\
\text { models appeared } \\
\text { most suited }\end{array}$ & $\begin{array}{l}\text { Statistical } \\
\text { interpolation is } \\
\text { most practical }\end{array}$ & $\begin{array}{l}\text { Hoek et al. } \\
(2008)\end{array}$ \\
\hline
\end{tabular}


Table 2. Characteristics of monitoring stations and target locations

\begin{tabular}{|c|c|c|c|}
\hline $\begin{array}{l}\text { Characteristic } \\
\text { Site Name }\end{array}$ & $\begin{array}{l}\text { Location } \\
\text { (Longitude, Latitude) }\end{array}$ & $\begin{array}{l}\text { Monitoring } \\
\text { site/ Target } \\
\text { Location }\end{array}$ & $\begin{array}{l}\text { Land Use/ } \\
\text { Major Activity }\end{array}$ \\
\hline Anand Vihar * & $\begin{array}{l}28.650278 \mathrm{~N}, \\
77.302778 \mathrm{E}\end{array}$ & Monitoring Site & Transport \\
\hline RK Puram* & $\begin{array}{l}28.56611 \mathrm{~N} 1 \\
77.176667 \mathrm{E}\end{array}$ & Monitoring Site & Residential \\
\hline Punjabi Bagh* & $\begin{array}{l}28.661944 \mathrm{~N} \\
77.124167 \mathrm{E}\end{array}$ & Monitoring Site & Residential \\
\hline Mandir Marg*,† & $\begin{array}{l}28.634167 \mathrm{~N} \\
77.200556 \mathrm{E}\end{array}$ & Monitoring Site & Commercial \\
\hline Aya Nagar & $\begin{array}{l}28.468881 \mathrm{~N} \\
77.127188 \mathrm{E}\end{array}$ & Monitoring Site & Residential \\
\hline Burari Crossing & $\begin{array}{l}28.728343 \mathrm{~N} \\
77.197495 \mathrm{E}\end{array}$ & Monitoring Site & Residential \\
\hline CRRI Mathura Road & $\begin{array}{l}28.551003 \mathrm{~N} \\
77.273836 \mathrm{E}\end{array}$ & Monitoring Site & Institutional \\
\hline DTU & $\begin{array}{l}28.749981 \mathrm{~N} \\
77.117236 \mathrm{E}\end{array}$ & Monitoring Site & Institutional \\
\hline IGI T3 & $28.554927 \mathrm{~N}, 77.0844 \mathrm{E}$ & Monitoring Site & Transport \\
\hline $\begin{array}{l}\text { IHBAS, } \\
\text { Garden }\end{array}$ & $\begin{array}{l}28.68115 \mathrm{~N} \\
77.304583 \mathrm{E}\end{array}$ & Monitoring Site & Institutional \\
\hline ITO & $\begin{array}{l}28.627521 \mathrm{~N} \\
77.243774 \mathrm{E}\end{array}$ & Monitoring Site & Commercial \\
\hline Lodhi Road & $\begin{array}{l}28.59246 \mathrm{~N} \\
77.236729 \mathrm{E}\end{array}$ & Monitoring Site & Commercial \\
\hline NSIT, Dwarka & $\begin{array}{l}28.609088 \mathrm{~N}, \\
77.03465 \mathrm{E}\end{array}$ & Monitoring Site & Institutional \\
\hline North Campus $\pi$ & $\begin{array}{l}28.687613 \mathrm{~N}, \\
77.21023 \mathrm{E}\end{array}$ & Monitoring Site & Institutional \\
\hline PUSA & $\begin{array}{l}28.63432 \mathrm{~N}, \\
77.170913 \mathrm{E}\end{array}$ & Monitoring Site & Institutional \\
\hline Shadi Pur & $\begin{array}{l}28.652533 \mathrm{~N} \\
77.155121 \mathrm{E}\end{array}$ & Monitoring Site & Commercial \\
\hline Siri Fort & $\begin{array}{l}28.54991 \mathrm{~N} \\
77.219907 \mathrm{E}\end{array}$ & Monitoring Site & Residential \\
\hline Mukarba Chowk & $\begin{array}{l}28.734917 \mathrm{~N}, \\
77.15579 \mathrm{E}\end{array}$ & Target Location & Industrial \\
\hline ISBT Kashmere Gate & $\begin{array}{l}28.669133 \mathrm{~N} \\
77.232001 \mathrm{E}\end{array}$ & Target Location & Transport \\
\hline Peeragarhi & $\begin{array}{l}28.67974 \mathrm{~N} \\
77.092688 \mathrm{E}\end{array}$ & Target Location & Transport \\
\hline
\end{tabular}




\begin{tabular}{llll} 
AIIMS & $28.567116 \mathrm{~N}$, & Target Location & Industrial \\
& $77.210046 \mathrm{E}$ & & \\
Geeta Colony & $28.653868 \mathrm{~N}$, & Target Location & Residential \\
Shahdara & $77.271231 \mathrm{E}$ & & \\
& $28.698056 \mathrm{~N}$, & Target Location & Residential \\
Shalimar Bagh & $77.290423 \mathrm{E}$ & & \\
& $28.716447 \mathrm{~N}$, & Target Location & Residential \\
Connaught Place $^{\boldsymbol{\alpha}}$ & $77.154089 \mathrm{E}$ & & \\
& $28.63281 \mathrm{~N}$, & Target Location & Commercial \\
IIT Delhi $^{\boldsymbol{\alpha}}$ & $77.219421 \mathrm{E}$ & & \\
& $28.545042 \mathrm{~N}$, & Target Location & Institutional \\
Tilak Nagar & $77.192465 \mathrm{E}$ & & \\
& $28.63858 \mathrm{~N}$, & Target Location & Residential \\
Rithala & $77.084849 \mathrm{E}$ & & \\
& $28.718362 \mathrm{~N}$, & Target Location & Residential \\
\hline
\end{tabular}

*Additional 4 months data apart from 24 months data is taken for these sites

${ }^{\pi}$ No data available for November 2017 from this monitoring site

${ }^{\alpha}$ No Kriging-based predictions are obtained for these sites for June 2015; July 2015; December 2015 and February 2016 to June 2016

$\dagger$ No data available for August 2016 for this site 
Figure 1. Monitoring stations and target locations. The distance between two prominent sites (Punjabi Bagh and RK Puram) is marked for a scale reference.

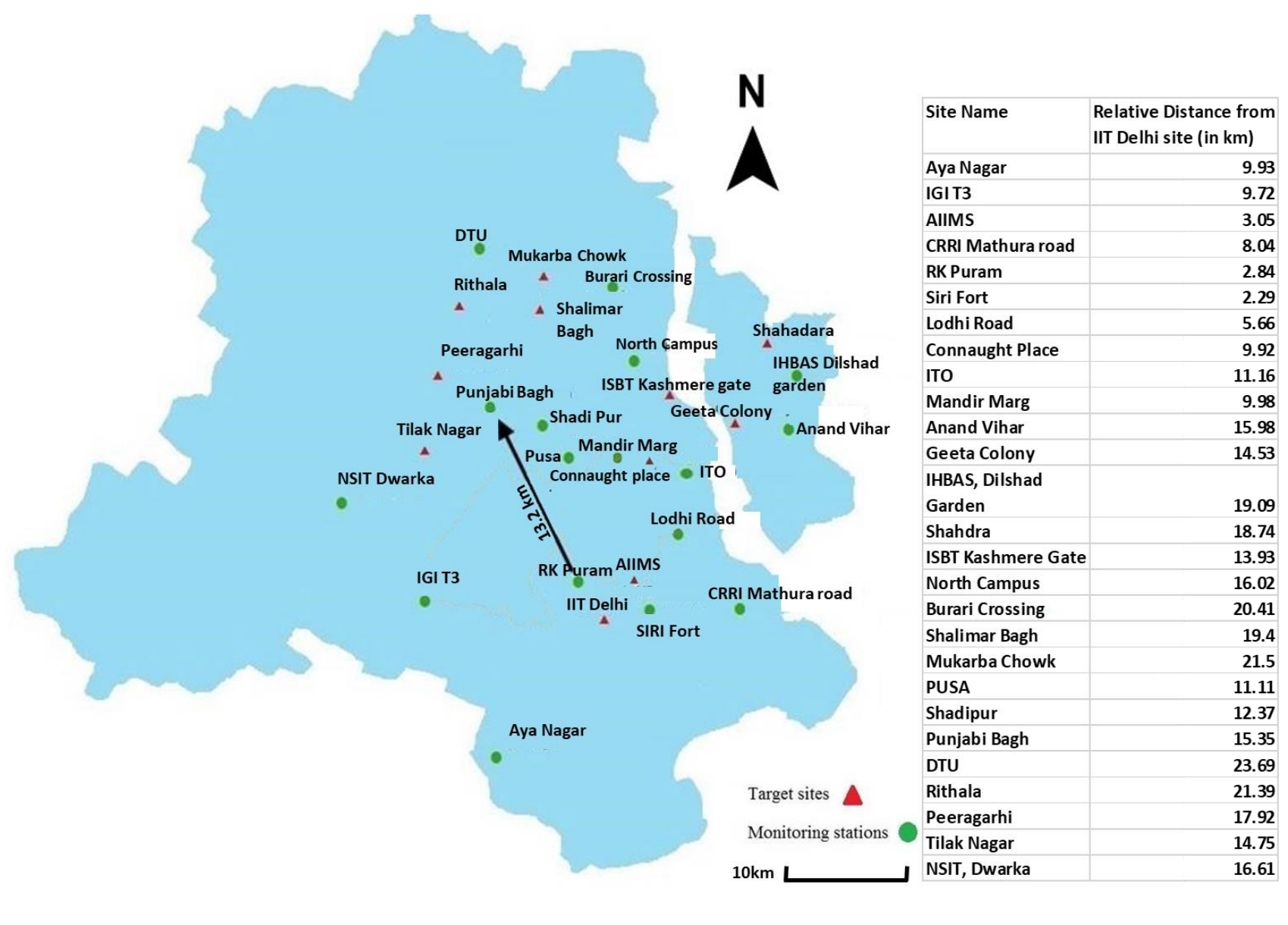


Figure 2. 24-Month time series of $\mathrm{PM}_{2.5}$ concentrations from 4 monitoring stations

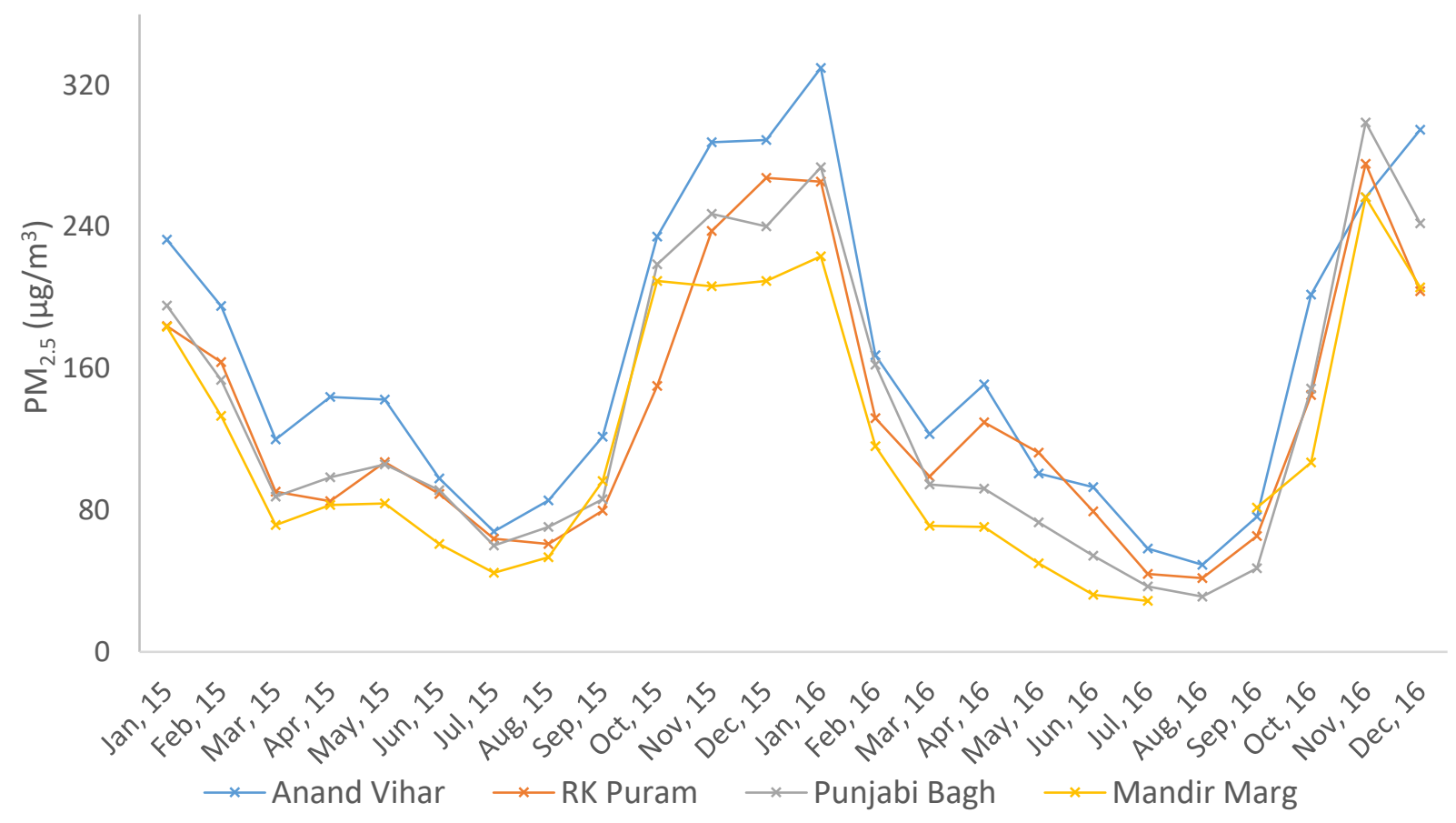


Figure 3. 4 Months monitored data for (a) Residential, (b) Transport and Commercial and (c) Institutional Land Use Monitoring sites.

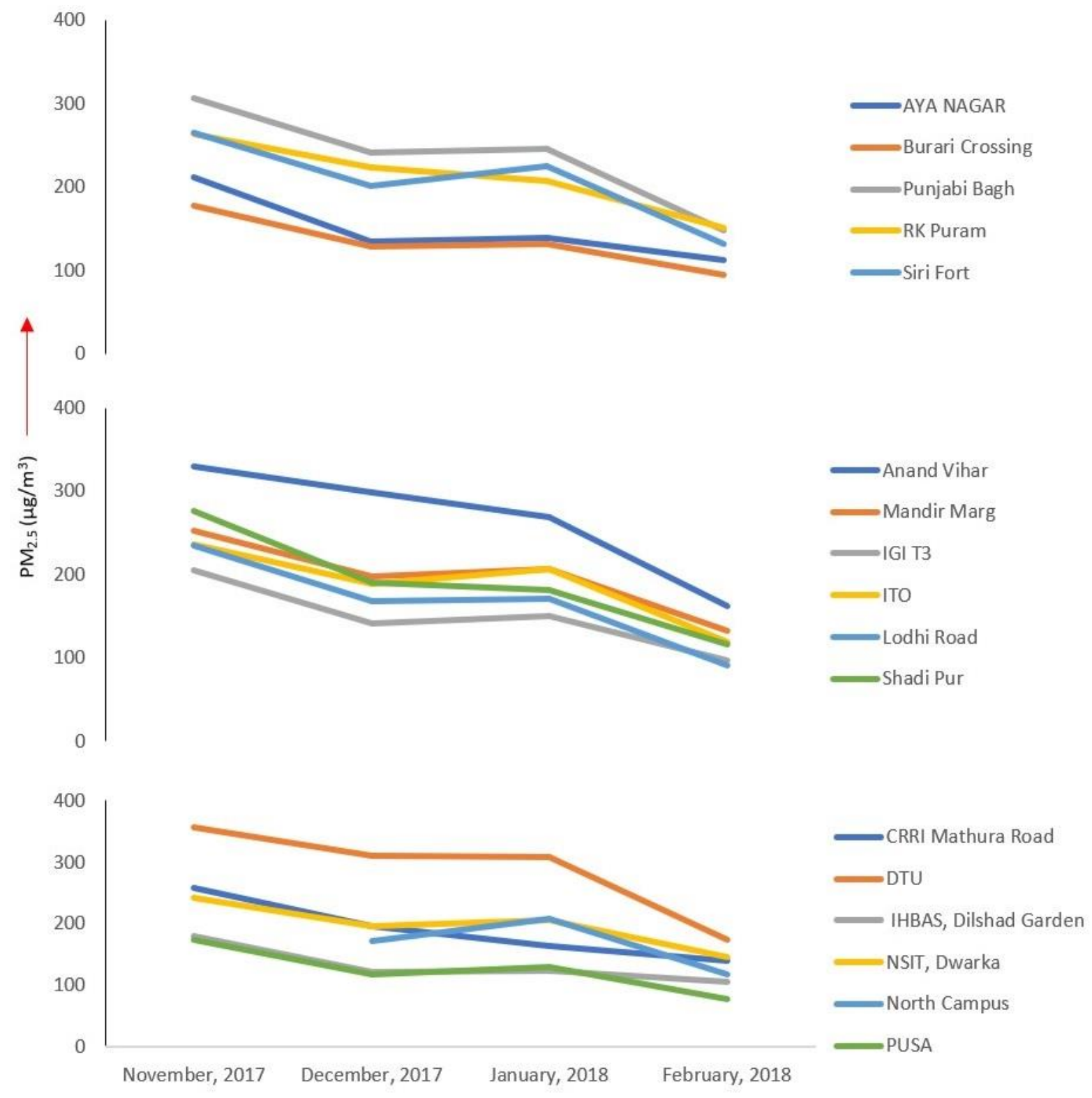


Figure 4 (a) Semivariogram exhibiting curve fit through covariance between concentration values of $\mathrm{PM}_{2.5}$ for December 2017. (b). Pure Nugget Effect observed for June 2015 exhibiting failure of Kriging method.

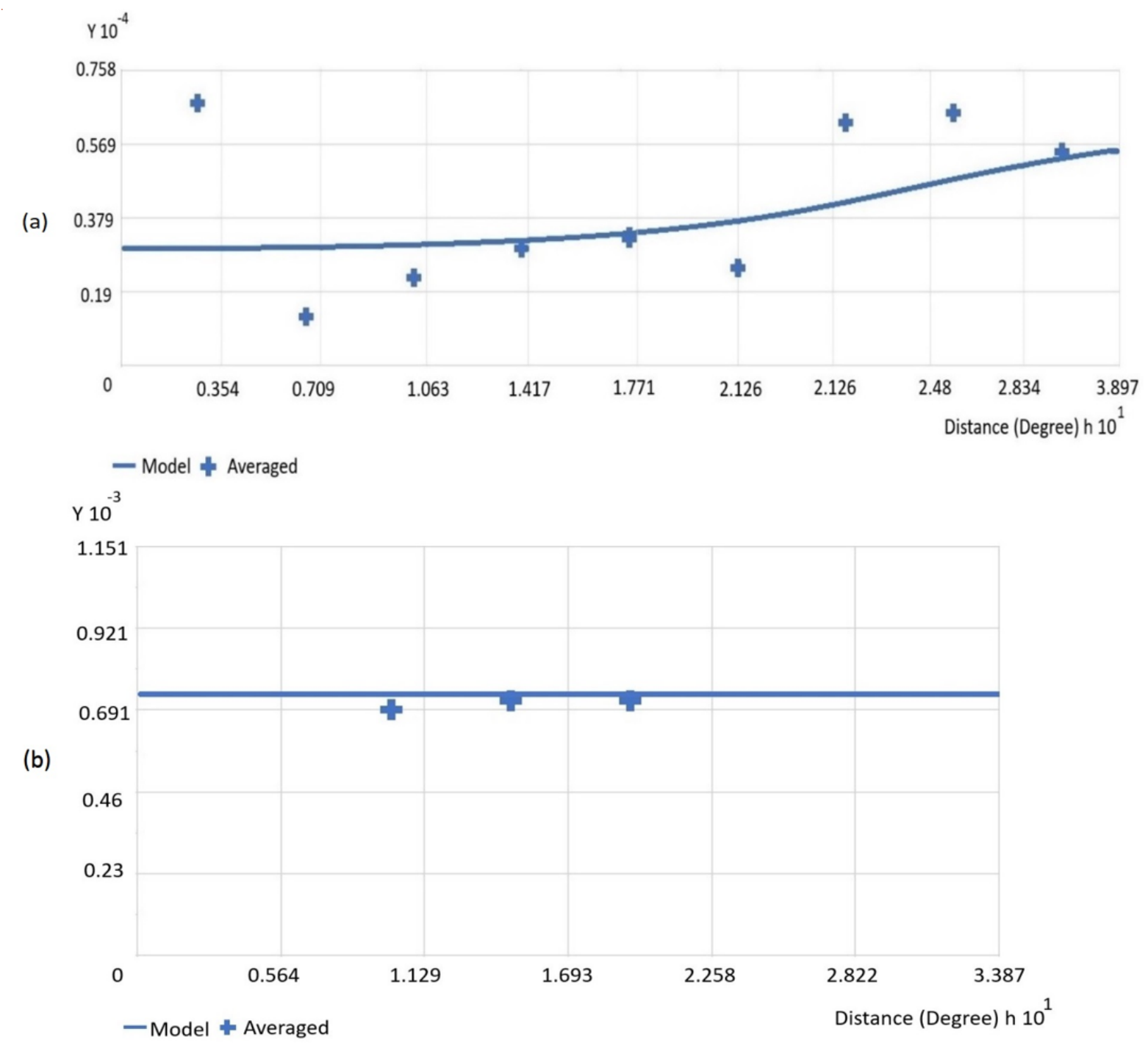


Figure 5 (a) Percentage error between the measured and predicted value at 4 monitoring sites for 24-month $\mathrm{PM}_{2.5}$ data (b) Percentage error between measured and predicted value at 17 monitoring sites for 4-month $\mathrm{PM}_{2.5}$ data

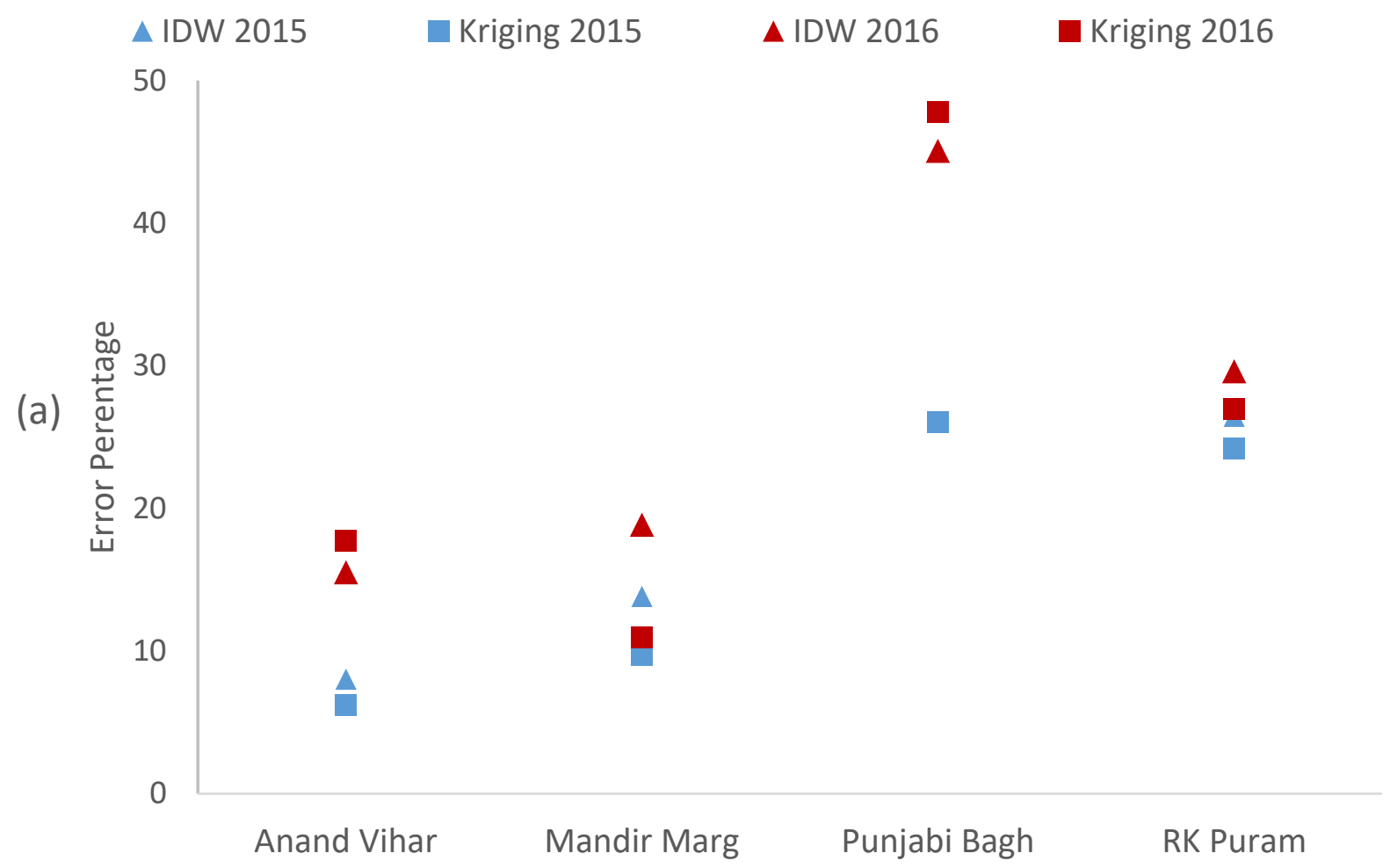




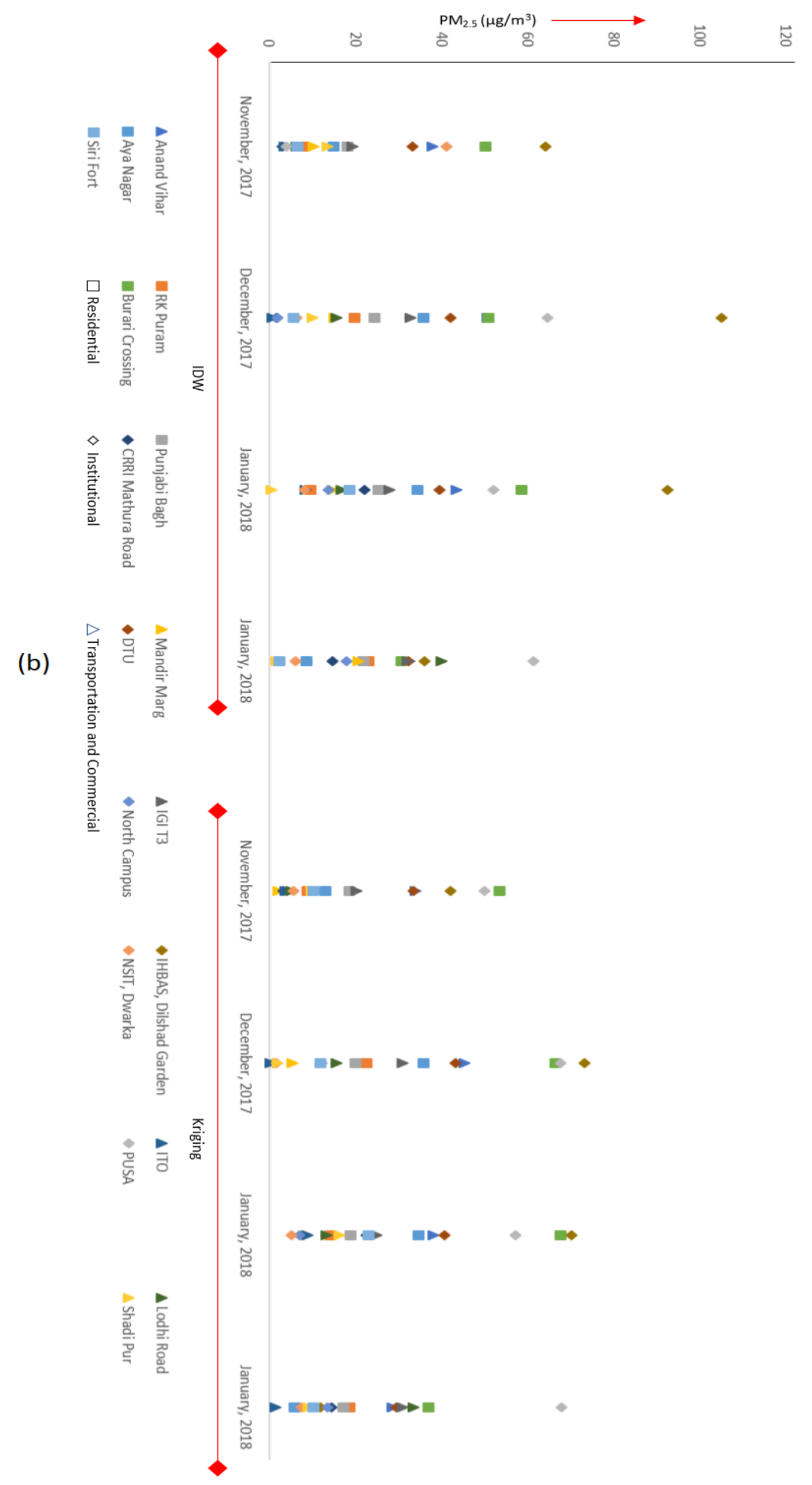

Accepted in Sustainable Cities \& Society Journal on 30.11.2019 
Figure 6 Predicted $\mathrm{PM}_{2.5}$ Concentrations at IIT Delhi and Connaught Place using (a) IDW and (b) Kriging

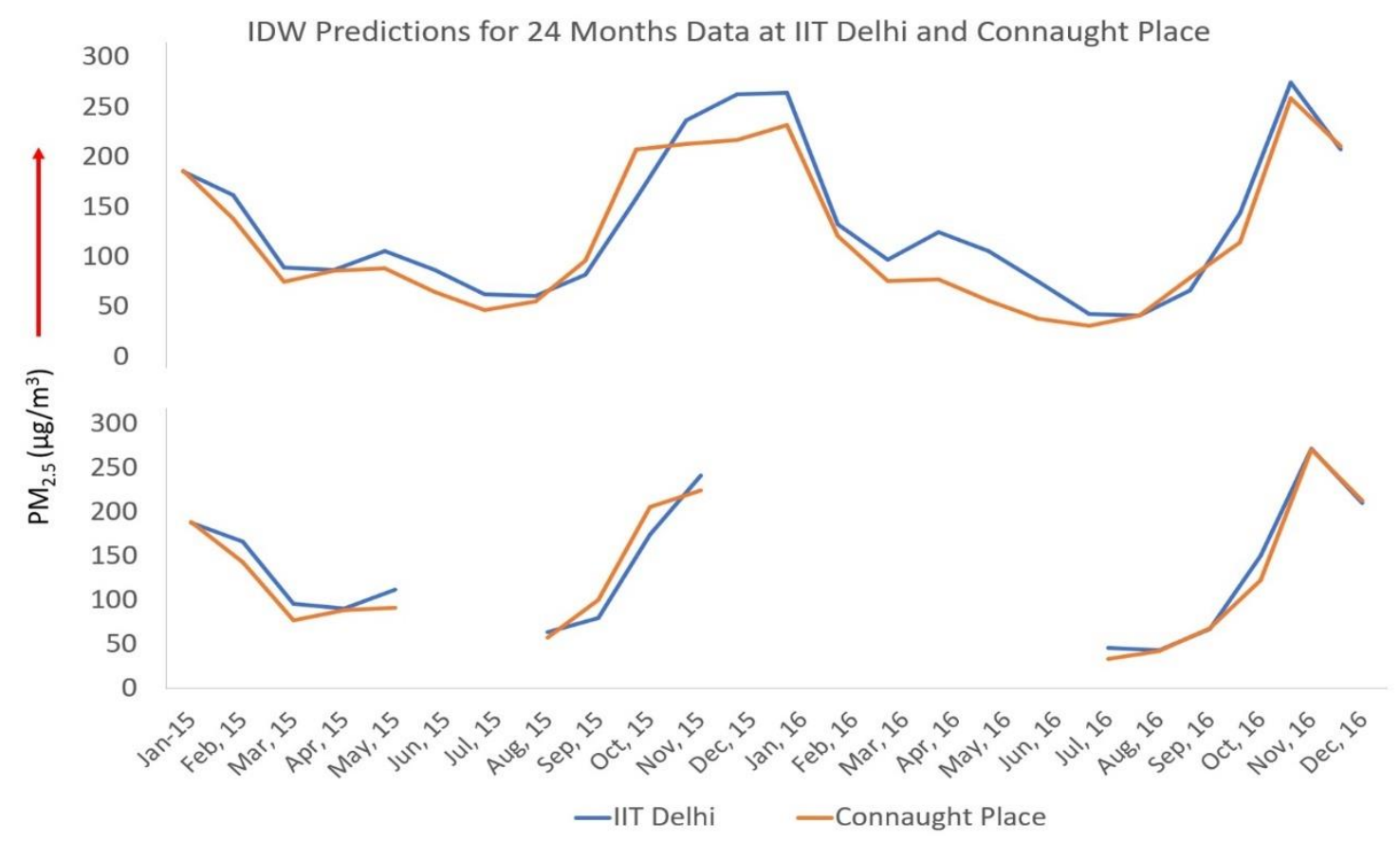

(a)

(b) 
Figure 7 Predictions for (a) residential and institutional locations (Kriging), (b) for Industrial, Transport and Commercial locations (IDW), (c) residential and institutional locations (Kriging) and (d) residential and institutional locations (IDW), between November 2017 and February 2018

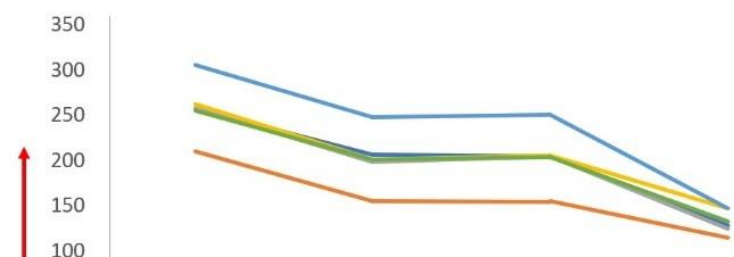

(a)

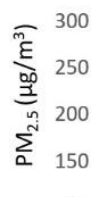
50 0

November, 2017 December, 2017 January, 2018 January, 2018

—Geeta Colony

- Connaught Place

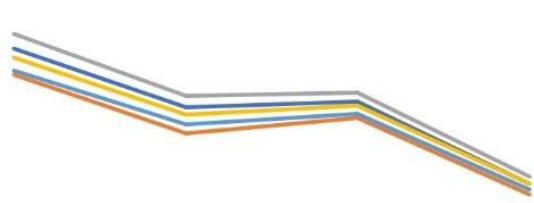

(b)

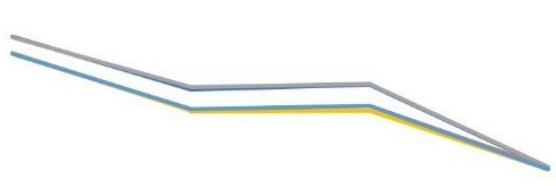

(d)

November, 2017 December, 2017 January, 2018 January, 2018

$\begin{array}{ll}\text {-Mukarba Chowk } & \text {-ISBT Kashmere Gate } \\ \text { —Peeragarhi } & \text {-AllMS }\end{array}$


Figure 8 (a; upper panel): Predicted surfaces using (i) IDW and (ii) Kriging for November 2017 to February 2018; (b; middle panel) IDW Predicted surfaces January 2015 to December 2016 at IIT Delhi campus and Connaught Place; (c; lower panel): Kriging Predicted surfaces January 2015 to December 2016 at IIT Delhi campus and Connaught Place

(i)

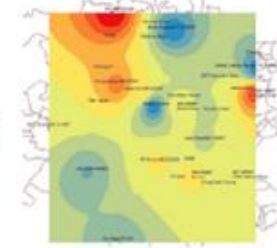

(a)

(ii)

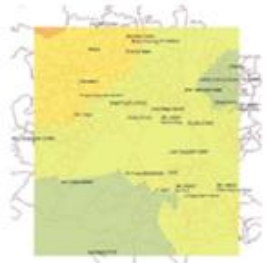

Nov 17

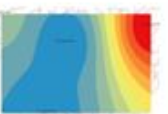

$\operatorname{Jan} 15$

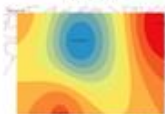

(b)

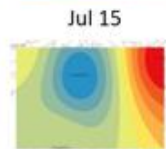

$\operatorname{Jan} 16$

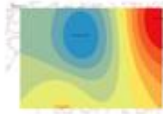

Jul 16

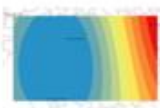

$\operatorname{Jan} 15$

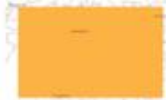

(c)

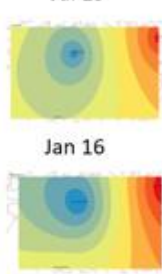

Jul 16

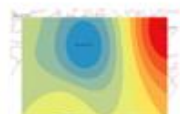

Feb 15

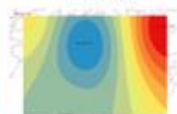

Aug 15

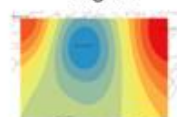

Feb 16

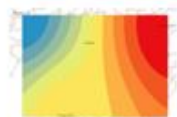

Aug 16

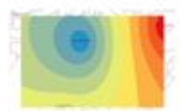

Feb 15

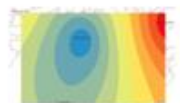

Aug 15

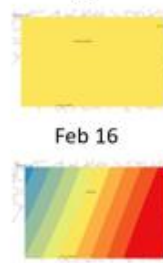

Aug 16

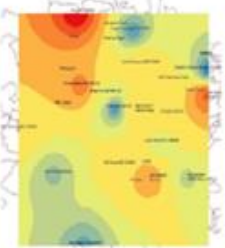

Dec 17

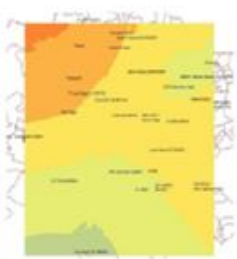

Dec 17

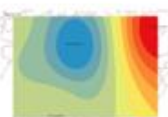

Mar 15

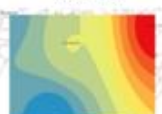

Sep 15

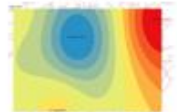

Mar 16

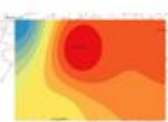

Sep 16

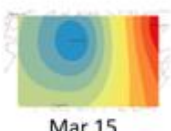

Mar 15

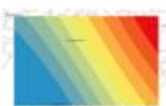

Sep 15

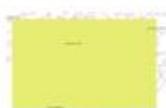

Mar 16

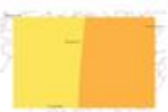

Sep 16

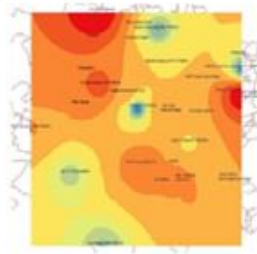

Jan 18

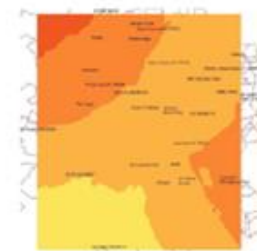

Jan 18
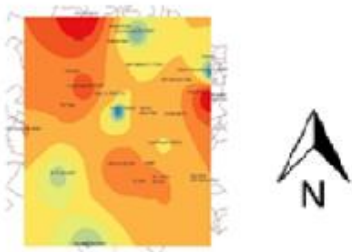

Feb 18

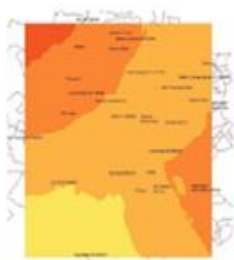

Feb 18

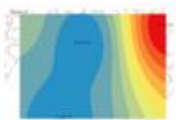

Apr 15

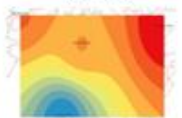

Oct 15

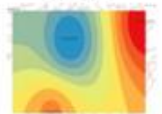

Apr 16

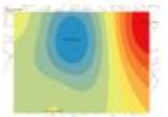

Oct 16

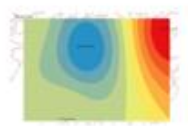

May 15

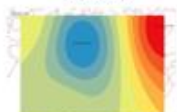

Nov 15

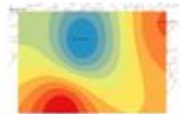

May 16

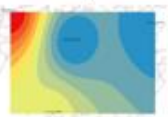

Nov 16

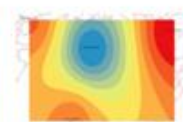

Jun 15

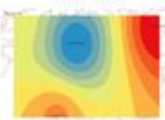

Dec 15

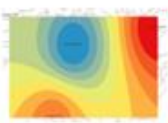

Jun 16

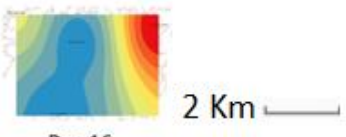

Dec 16

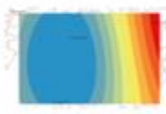

Apr 15

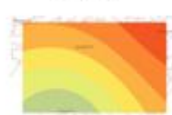

Oct 15

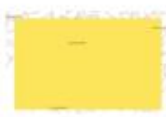

Apr 16

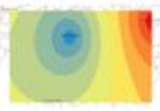

Oct 16

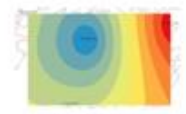

May 15

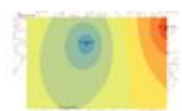

Nov 15

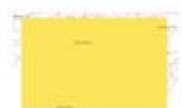

May 16

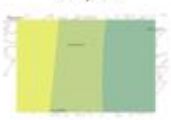

Nov 16

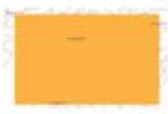

Jun 15

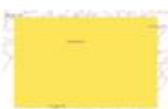

Dec 15

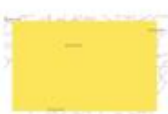

Jun 16

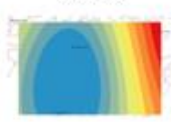

Dec 16
Highest*
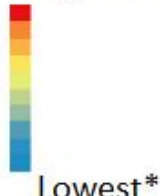

owest*

$\mathrm{Km}$

* The highest and lowest concentrations mapped on these predicted surfaces are for respective months only 
Accepted in Sustainable Cities \& Society Journal on 30.11.2019 